\title{
The effect of root and shoot damage on the growth of tea plants
}

\author{
T. Visser
}

Institute for Horticultural Plant Breeding, Wageningen, the Netherlands

Received 22 January 1969

\begin{abstract}
Summary
Under various conditions of elevation and climate, experiments were carried out in which young vegetatively propagated plants of selected tea clones were subjected to pruning operations at or after transplanting.

Generally the removal of a substantial portion of shoots, roots or both caused a temporary set back in growth and, in many instances, increased mortality. The subsequent reduction in total growth depended on the amount initially removed, except when only the immature apical part of the shoots was cut off, in which case the plants grew as well as the untreated ones. Retarded root growth and mortality as a consequence of pruning, are associated with a marked depletion of the carbohydrate reserves of the roots, which is more serious when the original level, in Ceylon primarily determined by altitude (temperature), is lower. Bringing a young tea-plant into bearing as soon as possible requires the induction of lateral branching while avoiding growth restriction as far as possible; in that respect 'bending' appears to fulfil this condition.
\end{abstract}

\section{Introduction}

In recent years more attention has been paid to the interaction of root and shoot growth of various plants. The investigations of e.g. Brouwer and co-workers (1963; $1965 \mathrm{a}, \mathrm{b}$; 1967) show that the partial removal of shoots (with leaves) is commonly followed by a stagnation of root growth, while shoot growth is initially checked if part of the root system is removed. Generally the plant appears to re-establish an equilibrium, in casu the shoot/root-ratio, within a relatively short time.

Most of these experiments have been carried out with herbaceous or deciduous plants grown under controlled conditions in nutrient solutions. Therefore, it may be of interest to relate the outcome of similar trials carried out under field conditions with the woody, evergreen tea plant at the Tea Research Institute of Ceylon between 1958 and 1962.

These trials were of direct practical importance because at that time a start was made with the replanting of hundreds of acres of seedling tea with superior (vegetatively propagated) clones involving hundreds of thousands of plants (5000 per acre). In these trials the effect of both root and shoot damage was studied because root damage may occur accidentally by transferring the plants from the nursery to the field and shoot damage is brought about purposely by pruning to assist frame formation. 


\section{Material and methods}

The plants used in these trials were grown from cuttings originating from clones selected for estate planting on account of their high yielding capacity. After the cuttings were rooted in the nursery, they were transferred into polythene bags (or bamboo baskets) filled with soil and, when sufficiently grown -8 to 12 months from propagation -, planted into the field. The replicated trials were carried out at 4 stations varying greatly in climate: Kottawa, Hantane, Passara and St. Coombs at an altitude of about $100,750,1050$ and $1350 \mathrm{~m}$, respectively.

\section{Results}

\section{Performance after root or shoot removal at transplanting}

The first three trials — summarily reported previously (Visser, 1963) — were carried out at Kottawa, Passara and St. Coombs with $5 \times 35$ (clone 2024), $7 \times 10$ (clone 2025) and $4 \times 10$ (clone 2025) plants per treatment, respectively, at Passara with plants grown in partly-deteriorated bamboo baskets, at Kottawa and St. Coombs with plants in polythene bags which were removed before transplanting.

The following treatments were applied at the time of transplanting:

a. control, untreated;

b. about one third of the weight of the roots removed;

c. about one third of the weight of the shoots removed;

d. about one third of both roots and shoots removed.

It should be noted that, tea being an evergreen plant, the removal of about one third of the shoots reduced the leaf area by about half. Both in these and the other trials extra plants were used to determine the dry weights of the roots and the shoots of control and treated plants at the beginning of the trial. The root and shoot weights of the plants were again determined 4-6 months later (the plants were then 14-16 months old) and are shown in Fig. 1.

It can be seen that at Kottawa and St. Coombs, where the plants grew initially in polythene bags, either shoot or root removal led to a significant reduction in subsequent growth; removal of both shoots and roots reduced growth still further. At Passara, only the partial removal of shoots decreased growth significantly, root removal had no effect. Presumably the transfer of plants growing in deteriorated baskets caused by itself a similar loss of roots in the untreated plants (see Kehl and Visser, 1961).

Fig. 1 also shows that the data represent a linear regression. This illustrates that the plants, though differing in size, had attained about the same shoot/root-ratio at the end of the trial, irrespective of their pre-treatment. From the fact that the tangents of the regressions of the three locations are about the same (the St. Coombs and Kottawa data actually represent one regression), it may be concluded that the plants reacted similarly notwithstanding marked climatic differences. These latter do show up in sofar the plants grew larger when the elevation was lower (temperature higher). Fig. 2 presents the weight of the plants at the end of the trial as a function of the loss in plant weight incurred by the different treatments at the start of the trial. Using total plant weights and expressing them as a percentage of the control, showed that the trends for the three locations did not differ significantly; this allowed the presentation of the average trend in one graph.

The relationship is significantly linear $(\mathrm{r}=0.93, \mathrm{n}=12)$, which means that within 


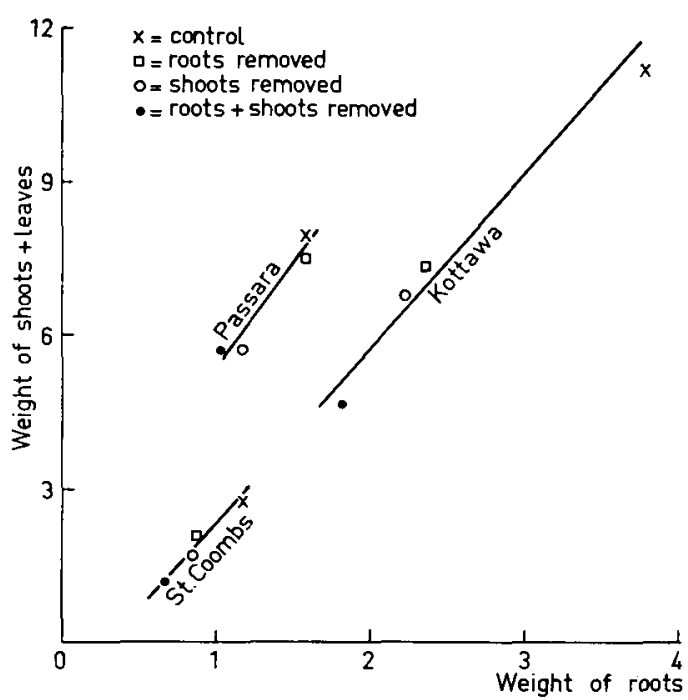

Fig. I The effect of the partial removal of shoots ( + leaves), roots or both on subsequent root and shoot growth (in $g$ dry weight) of young tea plants at 3 localities

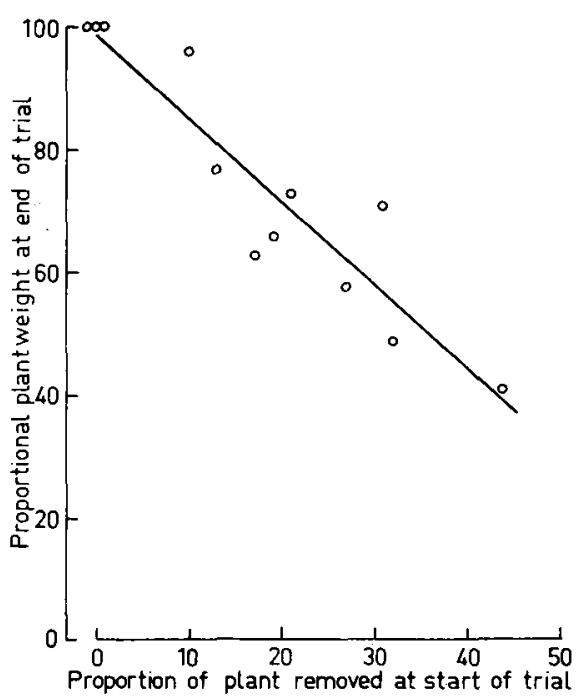

Fig. 2 The relation between the weight of plant parts removed (in \% of initial plant weight) and subsequent plant weight (in \% of the undamaged control) averaged for 3 localities: $y=98.6-1.35( \pm 0.17) x$

the limits of the trial, the reduction in total plant weight depended on the amount of plant material lost initially, whether the loss represented roots, shoots or both. This reduction in growth was quite substantial as plants which lost both roots and shoots, amounting to about $40 \%$ of their initial weight at transplanting, were on average less than half the size of the control plants 4-6 months later. Moreover, damaging the plants also decreased their chances of survival. At Kottawa and St. Coombs, where the trials started at the beginning of the dry season, respectively 34 and $70 \%$ of the most severely treated plants died as compared with 8 and $34 \%$ of the control. Few plants died at Passara where the trial period coincided with the wet season.

In the foregoing trials the plants were cut across at a certain height as a result of which both mature and immature wood and leaves were removed. It was thought that less damage might be done if only the tender (green-wooded) apical portions of the shoots were cut off ('thumbnailing' - see below), because these are likely to have a disproportionally high transpiration rate while drawing upon rather than contributing to the storage of assimilates. This was investigated at Kottawa, where the following treatments were compared:

a. control, untreated;

b. only green wood removed;

c. plants cut across at about two thirds of their height above ground level;

d. plants stripped of all leaves, inclusive removal of green wood.

The treatments $(5 \times 15$ plants each) were applied during the middle of the dry season to 14 months old plants of clone 2024 growing in polythene bags; they were subsequently transplanted (bags removed) in beds. 
Table 1 Dry weight (in $g$ ) of shoots and roots of plants 8 months after removal of a smaller or greater part of their shoots and leaves at transplanting (plant weight as a percentage of the control in brackets)

\begin{tabular}{lccccc}
\hline Treatment & $\begin{array}{c}\text { Weight } \\
\text { at start } \\
(\%)\end{array}$ & $\begin{array}{c}\text { Survived } \\
\text { at end } \\
(\%)\end{array}$ & $\begin{array}{c}\text { Shoot } \\
\text { weight } \\
(\mathrm{g})\end{array}$ & $\begin{array}{c}\text { Root } \\
\text { weight } \\
(\mathrm{g})\end{array}$ & $\begin{array}{c}\text { Total plant } \\
\text { weight } \\
(\mathrm{g})\end{array}$ \\
a. Control, untreated & 100 & 90 & 134.0 & 35.8 & $169.8(100)$ \\
b. Greenwood removed & 79 & 93 & 163.3 & 37.1 & $200.4(118)$ \\
c. Cut across & 77 & 79 & 127.2 & 29.8 & $157.0(92)$ \\
d. Stripped of leaves & 63 & 15 & 60.8 & 15.6 & $76.4(45)$ \\
Sign. diff. at P $=0.05$ & - & - & 29.6 & 9.7 & 37.9
\end{tabular}

Table 1 shows that the removal of the green-wooded part of the shoots (b) improved, while a cut across (c) depressed growth, though just not significantly, in comparison with the control. The significant difference between the two treatments in favour of the former, also in survival, is no doubt due to the qualitative difference (quantitatively the same) between the plant parts cut off initially. Therefore, at least under dry conditions such as in the trial, it would appear that the removal of immature plant parts may be advantageous or in any case do no harm. On the other hand, stripping the plant of all leaves (d) was found to be very harmful as it killed the majority of the plants and impeded the growth of the remaining ones very markedly.

\section{The effect of shoot damage after transplanting}

The tea plant when left by itself grows up to a small shrub or tree. As a leafproducing crop it is closely planted (e.g. at $0.6 \times 1.5 \mathrm{~m}$ ) and cultivated as a low, many-branched bush. It is therefore necessary to overcome its natural tendency to grow upright by treatments which stimulate branching. The effect of such 'bringinginto-bearing' treatments was investigated at St. Coombs using clones 777 and 2024. The main methods tested were:

a. 'bending'; the shoots are bent and pegged down horizontally, this is repeated with the shoots formed subsequently;

b. 'thumbnailing'; the tender apical parts of main and lateral shoots are pinched off more or less frequently;

c. 'cutting-across'; a horizontal prune at about two thirds of the height of the plant;

d. 'centering'; cutting the shoots so low that few or no leaves are left on the stumps. Modifications of these methods provided 10 treatments $(6 \times 7$ plants per clone per treatment), which ranged from little interference with growth to a drastic curtailment of it. The first treatments started when the plants were 12 months old, their root and shoot weights were assessed 11 months later. It appeared that removing the immature part of the shoots repeatedly $(7 \times$ 'thumbnailing') was as detrimental to growth as removing them altogether once ('centring'). Treatments in which the shoots were only partly cut through or partly broken, proved to be neither practical nor favourable to growth. Unfrequent thumbnailing (twice) gave better results, but the largest plants were obtained after a late and high cut-across or by bending, whether commenced earlier or later in the trial. Plant weight of the two latter treatments was about twice as high as that attained after e.g. centering or frequent thumbnailing. 


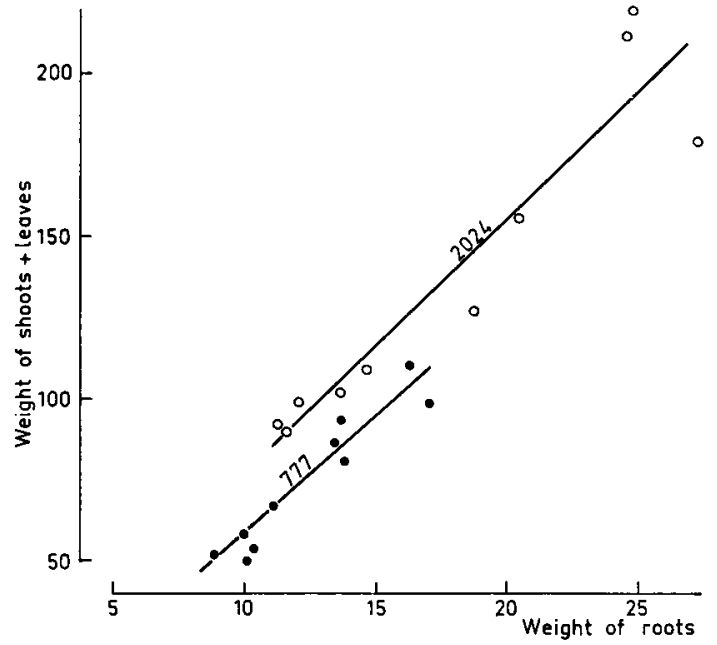

Fig. 3 Relation between root and shoot growth (in $g$ dry weight) of two tea clones subjected to various bringing-intobearing treatments involving different degrees of damage to the shoots

This trial produced the same results as the trials with younger plants, viz the plants grew larger the less they were disturbed.

As regards frame formation and taking into account plant size, bending was found to be the best method.

It was further observed that the shoot/root ratios of the variously treated plants differed insignificantly at the end of the trial as is illustrated by Fig. 3 which, as Fig. 1, shows a highly significant linear relation (correlation 0.95 ) between root and shoot weight. This relationship and the fact that the plants greatly differ in size, infers again that plant growth, primarily that of the roots, is subsequently reduced in proportion to the amount of shoots removed initially. From the fact that the regressions are approximately parellel, it may be deduced that the two clones, though greatly differing in vigour, reacted similarly upon the various treatments.

\section{Discussion and conclusions}

The different experiments produced essentially the same results, irrespective of differences in vigour between clones or in climate between locations. In all cases the plants, whether damaged below or above ground, tend to attain the same shoot/root ratio subsequently. The observations infer that, as with herbaceous plants (see Brouwer and co-workers, $1963 ; 1965 \mathrm{a}, \mathrm{b} ; 1967)$, the removal of shoots with their leaves primarily causes a stagnation of root growth, while a loss of part of the root system temporary reduces shoot growth. In either case subsequent growth of the plants is reduced in proportion to the loss sustained, while chances of survival are lessened.

The adverse effect of shoot removal on root growth results from a diminished supply of assimilates to the roots which effect is not compensated for by a decreased transpiration rate of the reduced leaf area. An exception on this rule was found to be the removal of the immature apical part of the shoots ('thumbnailing'). Similarly, Eden (1965) observed that wilting occurring during a drought in a close nursery stand of 
Table 2 Total carbohydrate reserves (in \% of dry weight) in roots of tea bushes before and after pruning at different altitudes (Visser, 1963)

\begin{tabular}{lcccc}
\hline Location & $\begin{array}{c}\text { Altitude } \\
(m)\end{array}$ & $\begin{array}{c}\text { Before pruning, } \\
\text { July '60 }\end{array}$ & $\begin{array}{c}\text { After pruning, } \\
\text { Dec. '60 }\end{array}$ & $\begin{array}{c}\text { After 7 months } \\
\text { plucking, July '61 }\end{array}$ \\
Hantane & 750 & 8 & 1 & 5 \\
Passara & 1050 & 11 & 3 & 5 \\
St. Coombs & 1350 & 19 & 8 & 11 \\
\hline
\end{tabular}

robust tea seedlings could be rectified by light 'skiffing' (removal of the shoot tops). Otherwise, as is shown by Table 2 for mature bushes, any substantial loss of (leafbearing) shoots e.g. due to pruning, leads to a marked depletion of the carbohydrate reserves in the roots.

This depletion can be such that a portion of the root system succumbs as a result of which the plant may die. Whether or not this happens depends on the root reserves initially present. These, apart from depending on plant age and season (lower or higher before or after a period of imposed dormancy), are in Ceylon, where tea is grown between 0 and $1800 \mathrm{~m}$, largely determined by altitude. The influence of this factor, as illustrated by Table 2 , was first investigated by Tubbs $(1935,1937)$ who ascertained that the carbohydrate reserves of tea roots linearly increase with increasing elevation, in casu with decreasing temperature (Visser, 1960). This finding gave an explanation of the variable response to 'clean-pruning' (reducing a densely-leaved bush to a low bare frame), which operation does not adversely affect up-country tea (above $1300 \mathrm{~m}$ ), but causes severe die-back and often the death of the bush at low elevations. More recently a similar difference related to altitude was noted in the success or failure of newly planted clonal areas (Anon., 1963). The difficulties experienced with pruning low-country tea were overcome by the application of 'lungpruning', in which case a few branches with their foliage ('lungs') are temporary left unpruned. By this means survival may be greatly improved as was also observed by Tolhurst (1964) at Hantane where bushes of clone 2024 recovered well after lungpruning, while the majority died after clean-pruning, presumably due to low root reserves (see Table 2). The advantage of the continued assimilation by the 'lungs' is reflected in the root reserves which appear to decrease less and at a slower rate than occurs after clean-pruning (Nagarajah and Pethiyagoda, 1965).

As regards 'bringing-into-bearing' treatments, the aim of obtaining a well-branched plant with the least interference with growth was achieved best by 'bending'. The fact that the bent plants were no heavier than the plants subjected to a late and high cut-across, indicates - as found in similar trials with fruit trees - that also bending inhibits growth to some extent. However, taking into account both plant size and frame formation, bending appears to be the quickest method to form a productive bush (Perkins, 1950; Worthington, 1962; Brandam-Jones et al., 1965). As such, the evergreen tea plant has in common with deciduous fruits as apple and pear, that the productive stage is reached earliest when growth is disturbed least (Visser, 1964).

\section{Acknowledgments}

I am much indebted to my former co-workers Messrs F. A. Kehl and L. M. de W. Tillekeratne for their assistance in carrying out the experiments. 


\section{References}

Anonymous, 1963. Survival of clonal tea in drought areas. Tea $Q$. 34: 22-33.

Brandam-Jones, R. et al., 1965. Bringing young tea into bearing. Tea 6 (3) : 9-22.

Brouwer, R., 1963. Some aspects of the equilibrium between overground and underground plant parts. Jaarb. Inst. biol. scheik. Onderz. LandbGewass. 1963: 31-39.

Brouwer, R., 1967. Beziehungen zwischen Sprosz- und Wurzelwachstum. Angew. Bot. 41: $244-254$.

Brouwer, R. and Kleinendorst, A., 1965a. Effect on root excision on growth phenomena in perennial ryegrass. Jaarb. Inst. biol. scheik. Onderz. LandbGewass. 1965: 11-20.

Brouwer, R. and Locher, J. Th., 1965b. The significance of seminal roots in growth of maize. Jaarb. Inst. biol. scheik. Onderz. LandbGewass. 1965: 21-28.

Eden, T., 1965. Tea. Trop. Agr. Series, 2nd ed. Longmans, Green \& Co, London.

Kehl, F. H. and Visser, T., 1961. Polythene bags versus bamboo supply baskets. Tea $Q$. 32: 213-215.

Nagarajah, S. and Pethiyagoda, U., 1965. The influence of 'lungs' on carbohydrate reserves and growth of tea shoots. Tea $Q .36: 88-102$.

Perkins, G. G., 1950. A method for bringing tea plants into bearing without centering. Tea $Q$. 21 (2): 4.

Tolhurst, J. A. H., 1964. Pruning clone T.R.I. 2024; observations in the mid-country. Tea $Q .35$ : $174-175$.

Tubbs, F. R., 1935. Report of the Plant Physiologist for 1934. Bull. Tea Res. Inst. Ceylon 12 32-39.

Tubbs, F. R., 1937. Investigations on the planting, pruning and plucking of the tea bush. Bull. Tea Res. Inst. Ceylon 15: 59 pp.

Visser, T., 1960. Carbohydrate studies. Rep. Tea Res. Inst. Ceylon 1959: 84-86.

Visser, T., 1963. Growth observations on young tea plants; carbohydrate analysis. Rep. Tea Res. Inst. Ceylon 1961: 111-115.

Visser, T., 1964. Juvenile phase and growth of apple and fruit seedlings. Euphytica 13: 119-129.

Worthington, C. J., 1962. Bringing tea into bearing: to prune or to bend? Tea $Q$. 33: 166. 